\title{
Impact Response of Circular Aluminum Tube Filled with Polyurethane Foam
}

\author{
Nirut Onsalung, Chawalit Thinvongpituk* and Kulachate Pianthong \\ Department of Mechanical Engineering, Faculty of Engineering, Ubon Ratchathani University, \\ Warinchamrab, Ubonratchathani 34190, Thailand
}

The behavior of foam-filled thin-walled aluminum tube under impact was investigated focusing on different crashworthiness parameter. The diameter to thickness of tube ranging between 26.5 and 200 were filled with polyurethane foam density from $100-250 \mathrm{~kg} \cdot \mathrm{m}^{-3}$. The specimens were crushed by a drop hammer. The result from finite element simulation and experiment was compared and good agreement was achieved. The simulation was also used to conduct further investigation on tube with higher diameter to thickness ratio. It was found that by filling foam, the tubes change their collapse modes from asymmetric mode to axisymmetric mode. Also, the energy absorption can be enhanced by filling tube with higher foam density. The impact energy was found to be managed more efficient in foam filled tube as the load efficiency is higher in higher density foam-filled tube. However, the specific energy absorption of foam-filled tube is getting lower in higher density foam. This paper provides experimental and numerical data as well as discussion in various aspects of crashworthiness. [doi:10.2320/matertrans.M2013293]

(Received July 31, 2013; Accepted October 29, 2013; Published December 25, 2013)

Keywords: polyurethane foam, energy absorption, finite element, aluminum tube, collapse mode

\section{Introduction}

The occupant safety is one of the most important criteria in design of vehicle structures with the aim to minimize injury and protect occupants. While accident occurs, the frame of an automobile is the most important part that dissipates reaction force to be energy which shall be absorbed by its structure. In general, an automotive structure is assembled from various members that fabricated from many kinds of metallic shells, such as circular tube, rectangular tube or curved sheet. These structures are known as efficient impact energy absorbers. The investigation of structure under impact condition was referred to as "crashworthiness study". In the view of crashworthiness, thin-walled structures are often used under static and dynamic axial loading. ${ }^{1-3)}$ Alexander ${ }^{4)}$ specified a theoretical formulation to compute the mean collapse load for the circular tubes deforming in concertina mode. His model revealed deformation on the plastic line of collapse and gave the average crushing load through collapse mechanism analysis. Since then, it has been continuously investigation from his model to develop more effective model. ${ }^{5-7)}$ Mamalis et $a{ }^{8}{ }^{89}$ ) used finite element analysis (FEA) to predict the crushing behaviour of tube under axial load. Langseth et al. ${ }^{10,11)}$ studied the crashworthiness of square tubes under static and dynamic load using LS-DYNA and compared with experimental results. They also focused on the influence of mass and velocity of impact hammer. Some researchers have done experimental and theoretical studies in metal tubes with various cross-sections and thickness which reported by $\mathrm{Nia}$ et al. ${ }^{12)}$ and Yamasita et al. ${ }^{13)}$ Also, axial impact experiments and simulation studies on cylindrical tube of various diameter to thickness $(D / t)$ ratio were conducted by free fallen hammer by Gupta. ${ }^{14)}$

As being a main body of vehicle structure, tubes as well as other shells should be lightweight in order to decrease fuel consumption. In this current, the thin-walled structure is very interested because it is strong and light weight. ${ }^{15)}$ Especially, the frontal components of car such as the side rails and front

*Corresponding author, E-mail: chawalit@rocketmail.com beam must be highest energy absorption. ${ }^{16,17)}$ For instance, Li et al. ${ }^{18)}$ study the impact of car structure made from lightweight high strength steel sheet using simulation. Huh et al. ${ }^{19)}$ investigated the crushing behaviour of automotive members such as front side member by considering the fabrication histories. In addition, there are many researches using lightweight material fill core or cover thin-walled tube for enhance the stiffness and energy absorption capacity of the structural members. ${ }^{20)}$ The applications of cellular solids such as porous materials have received interest in recent years. The filling of structural member with foam material for increasing energy absorption capacity has also been taken considerable interest. Common to all foam materials are the attributes of high porosity, light weight, high crushability and good deformation energy absorption capacity. ${ }^{21,22)}$ The article on crushing behavior of foam-filled thin-walled tubes was conducted by Hanssen et al. ${ }^{23)} \mathrm{He}$ used aluminum foam-filled square aluminium tubes for studying the influence of foam density by using the quasi-static load. A year later, he developed an empirical model for the mean crushing load of foam filled circular and square columns by using experiment under quasi-static and dynamic loading conditions. ${ }^{24,25)}$ The numerical and experimental studies on the crush response of foam-filled sections under axial load were continuously studied by other researchers. ${ }^{26-28)}$ There are many types of foam material that used to fill into the structural members. ${ }^{29,30}$ ) Among those, polyurethane (PU) foam is one of the light weight material that often used to reduce the weight of members as can be found in some reports. ${ }^{31)}$ Ghamarian et $a l .{ }^{32)}$ study PU foam-filled end-capped thin-walled circular aluminum tubes under quasi-statics axial crush. They used the finite element (FE) simulation by using crushable foam model in ABAQUS/Explicit to compare with the experimental results. Similar study was done by Mirfendereski, ${ }^{33)}$ he determined the energy absorption capacity using crushable foam model in ABAQUS compared with experimental results.

The main objective of this paper is to investigate the crush behaviour of PU foam-filled aluminium tube and describes experimental and numerical simulation under axial impact. The circular aluminium tubes with various ratios of $D / t$ are 
included in the study. There are four different densities of rigid PU foam filled into the tube. The specimens were tested by free fall drop hammer. The influences of foam density to stroke displacement, mode of collapse, and energy absorption are focused. In addition, the FE simulation was performed to compare with experimental result.

\section{Methodology}

\subsection{Parameters definition}

Generally, there are various kinds of characterization parameters that used to evaluate the performance of energy absorption element. The load-displacement response of energy absorbing devices can primarily measure their energy absorption performance. In this paper the load efficiency $\left(P_{\mathrm{e}}\right)$, the energy absorption $\left(E_{\mathrm{a}}\right)$ and the specific energy absorption $\left(E_{\mathrm{s}}\right)$ are used as key indicators. Normally, the impact force will be deformed in a pattern of energy and stored into hinge line of structural fold. ${ }^{34)}$ The energy absorption is defined as an integration of the area under load-displacement curves. For all specimens under crushing, the collapse process is terminated when the structure is bottomed-out or fully collapsed. By over loading a specimen after full collapse, the load will be, of course, raised sharply. However, the energy absorption in the region after full collapse is unrelated to the usefulness of the structure. Therefore, only the energy absorption based on the load before complete collapse is considered.

The energy absorption of a structure can be approximated by eq. (1). The structure under impact load should be high energy absorption when compared to the mass of the device. This is concerned throughout the specific energy absorption which is an important criterion for lightweight design. Generally, only the crushed mass of an absorber is taken into account. However, in some complex structures which the crushed mass is difficult to measure, the total mass of the structure may be used. This parameter is obtained by dividing the energy absorption by mass as shown in eq. (2). The load efficiency is defined as the ratio of mean load to maximum load. This parameter is a useful measurement to indicate the uniformity of the crush loads. For an ideal energy absorber, the load efficiency may be very close to $100 \%$. Lower load efficiency implies to high acceleration which may be harmful to passenger in vehicles. The load efficiency can be calculated from eq. (3).

$$
\begin{aligned}
& E_{\mathrm{a}}=\int_{0}^{S} P d S \approx P_{\text {mean }} \cdot S \\
& E_{\mathrm{s}}=E_{\mathrm{a}} / \text { mass } \\
& P_{\mathrm{e}}=P_{\text {mean }} / P_{\text {max }}
\end{aligned}
$$

Where $S$ is the crushing stroke of a deformed specimen, $P$ and $P_{\text {mean }}$ is the instantaneous crushing load and average crushing load respectively, $P_{\max }$ is a maximum point on loaddisplacement curve, and mass is the total mass of tube and foam.

\subsection{Material and properties}

The circular aluminum extrusions used in this test were made up of alloy A6063-T5. The sample was cut from tube wall along its axial direction for mechanical property testing.

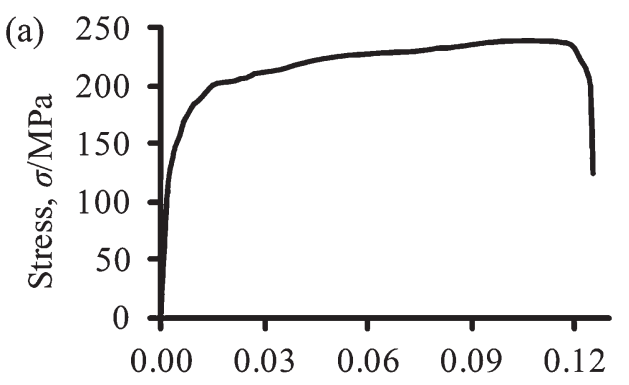

Strain, $\varepsilon$

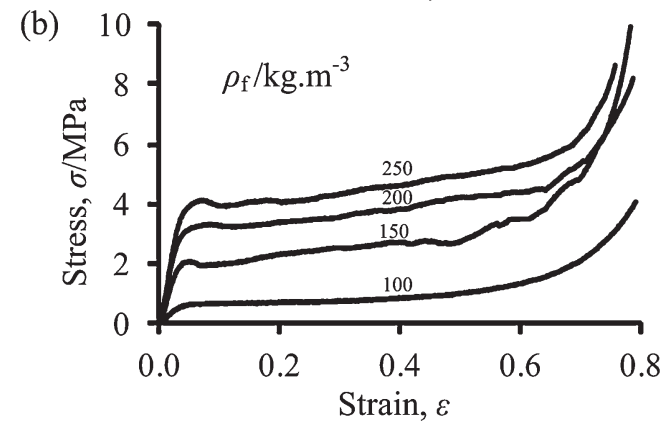

Fig. 1 Stress-strain curve on uniaxial test: (a) aluminium tube and (b) polyurethane foam with different densities.

The standard test method for tension testing of metallic material (ASTM E8M) was applied using the ESH 2,000 kN universal testing machine. Axial force and deflection were recorded digitally using $\mathrm{PC}$ based data recording equipment. The mechanical properties of specimens are Young's modulus $68.7 \mathrm{GPa}$, ultimate tensile strength $245 \mathrm{MPa}$, yield stress $187 \mathrm{MPa}$ and Poisson's ratio 0.3 .

The PU foam used in this study is a mixture of two chemical substances; i.e., Polyol and Isocyanate. They were mixed in a ratio of $1: 1$ in liquid form. The mixture was, then, injected into the specimens with different densities. The mixture was allowed to expand inside the tube for about $10 \mathrm{~min}$ for completely expansion. The properties of PU foam with different density were tested by cut each foam column into $50 \times 50 \times 50 \mathrm{~mm}^{3}$ cube. They were, then, tested under uniaxial compression with a speed of $5 \mathrm{~mm} \cdot \mathrm{min}^{-1}$. Figure 1(a) shows the engineering stress-strain curve of aluminium tubes obtained from standard test. The property of each density of PU foam is shown in Fig. 1(b).

\subsection{Specimen preparation and finite element modeling}

The specimens were performed on commercially available aluminium cylindrical tube of different diameters and thicknesses with $D / t$ ratio $26.5-42.3$ for experiment. The simulation was also done on tube with $D / t$ ratio $26.5-42.3$ in order validate the model. Then, the FE model was further used to simulate tubes with $D / t$ between 100,150 and 200 . Those tubes are every thin, difficult to be fabricated and cannot be found in common market. Therefore, the simulation model was used. The geometrical parameters of specimens are shown in Table 1. Each tube was filled with PU foam of different densities, which are 100, 150, 200, and $250 \mathrm{~kg} \cdot \mathrm{m}^{-3}$. The value of foam density was checked using Seitzberger recommendation. ${ }^{35)}$ Initial high of aluminium tube before filling with PU foam is $200 \mathrm{~mm}$ height. After filled with PU foam, the tubes were cut at both ends to have 
Table 1 Geometrical parameter of specimens.

\begin{tabular}{ccccc}
\hline$D / \mathrm{mm}$ & $t / \mathrm{mm}$ & $D / t$ & EXP & FEA \\
\hline 31.8 & 1.2 & 26.5 & $\checkmark$ & $\checkmark$ \\
41.3 & 1.3 & 31.7 & $\checkmark$ & $\checkmark$ \\
44.5 & 1.2 & 37.0 & $\checkmark$ & $\checkmark$ \\
50.8 & 1.2 & 42.3 & $\checkmark$ & $\checkmark$ \\
50.8 & 0.508 & 100 & & $\checkmark$ \\
50.8 & 0.338 & 150 & & $\checkmark$ \\
50.8 & 0.254 & 200 & & $\checkmark$ \\
\hline
\end{tabular}

(a)

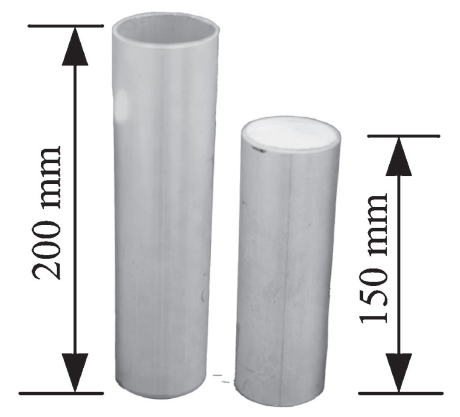

(b)

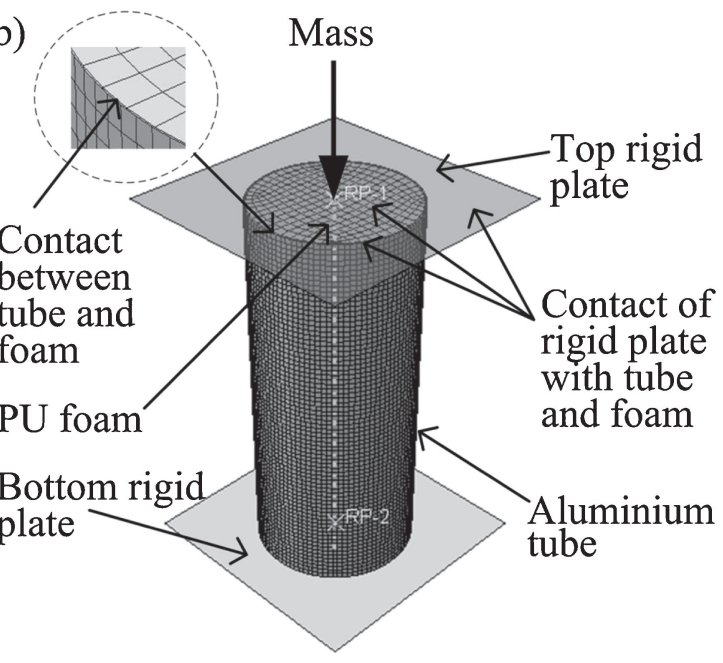

Fig. 2 Specimens and modeling preparation: (a) the specimen before and after foam-filled and (b) FE modeling with contact condition.

$150 \mathrm{~mm}$ height. Typical specimens before and after foamfilled are shown in Fig. 2(a). The specimens were made in triplicate in order to repeat the test. Therefore, there were totally 60 pieces of specimen, including empty tubes.

The geometrical modeling was created in a commercial FE package code ABAQUS. The detail and configuration of contact boundary condition in FE are shown in Fig. 2(b). The FE model is consisted of four parts i.e., top rigid plate, bottom rigid plate, aluminium tube, and PU foam column. At top and bottom of tube the rigid plates were created with a reference node at center. The element type of both rigid bodies are 4-node, bilinear quadrilateral R3D4. The tube and foam are modeled with 8-node linear brick element C3D8R. Mesh independent of the FE model was made and optimum mesh size was archived for tube and foam column. The foam column was modeled to be crushable isotropic hardening with $k=1$ and $v_{\mathrm{p}}=0,{ }^{36)}$ where $k$ is the compression yield

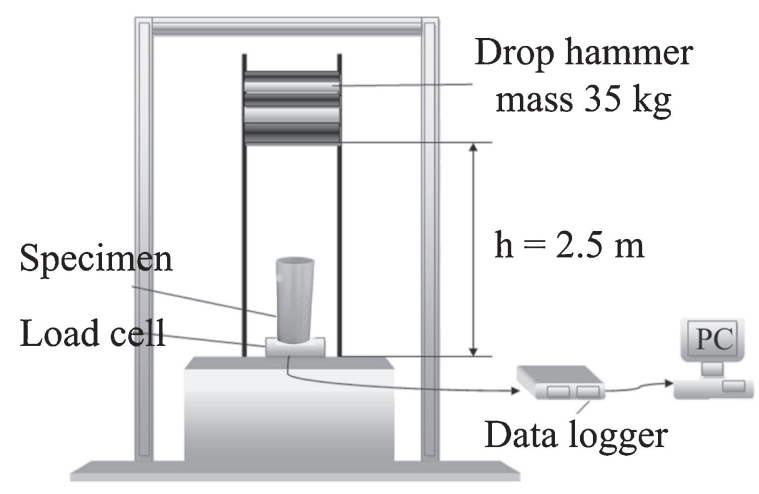

Fig. 3 Illustrate of impact testing system.

stress ratio and defined as the ratio of initial yield stress in uniaxial compression to initial yield stress in hydrostatic compression and $v_{\mathrm{p}}$ is plastic Poisson's ratio. The value of friction is 0.2 in every contact surfaces i.e., rigid plat and foam, rigid plate and tube, tube and foam, according to Santosa's recommendation. ${ }^{37}$ )

\subsection{Experimental procedures}

For experimental procedure, the axial impact tests were carried out on a drop hammer testing apparatus as shown in Fig. 3. The impact was made by dropping $35 \mathrm{~kg}$ hammer from $2.5 \mathrm{~m}$ height. The velocity of hammer at impact is about $7 \mathrm{~m} \cdot \mathrm{s}^{-1}$. The reaction force during impact was measured and recorded by load cell and data logger. In case of the FE simulation, the models were assigned to define the boundary condition and behaviors of specimen in FE model same as experimental condition. True stress and plastic strain of aluminum tube and of PU foam were calculated from test result and shown in Table 2. They were assigned to define the behavior of specimen in FE model.

\section{Results and Discussions}

\subsection{Load-displacement response}

While the specimens are being crushed, the reaction force corresponding to stroke displacement are recorded and plotted on the load-displacement curve pattern. Normally, the area under load-displacement curves is used to determine the energy absorption. The impact energy will be stored in folds of collapse tube. The typical load-displacement curves of experiment and FE model of empty and foam-filled tubes in this study are shown in Fig. 4. The curves are normally fluctuating in wavy shape. Each loop of the curve is corresponding to a lobe in the deformed tubes. The FE simulation result tends to have higher value in the initial peak. The following loops generally swing in a narrow range of magnitude. Considering the result from experiment, it is observed that the load is not highly varied. It is also observed that the mean loads from FE model and experiment are in the same range.

Considering the experimental result shown in Fig. 4, it is also noticed that the crush strokes of tubes, in every $D / t$ value, tend to decrease from empty tube to higher density of foam fill tubes. This is because higher density foam reduces the free volume in tube, resulting in shorter stroke. However, 
Table 2 True stress and plastic strain of aluminium tube and polyurethane foam.

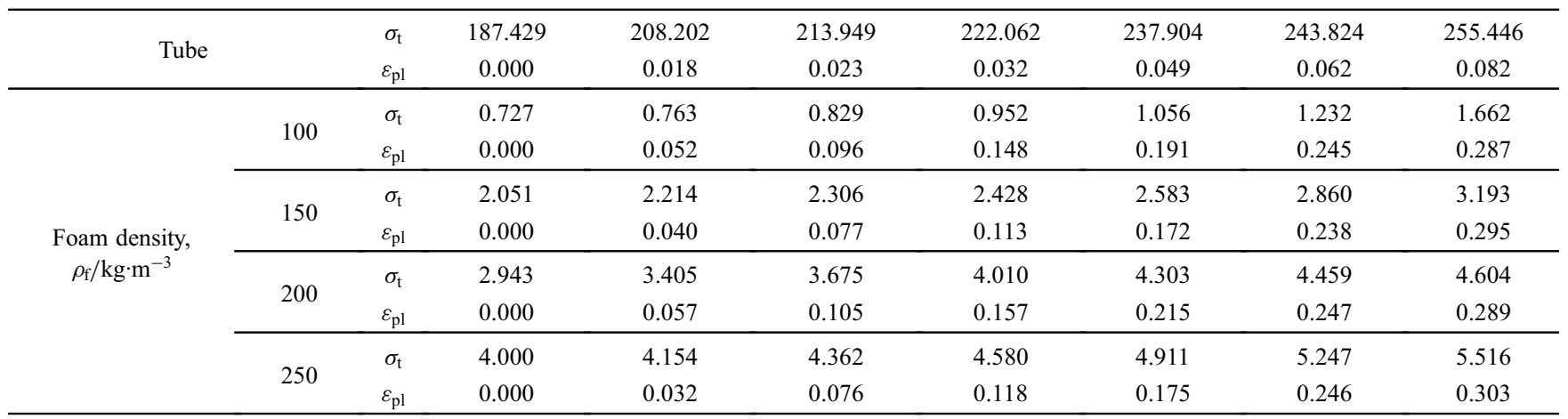

$\sigma_{\mathrm{t}} / \mathrm{MPa}$

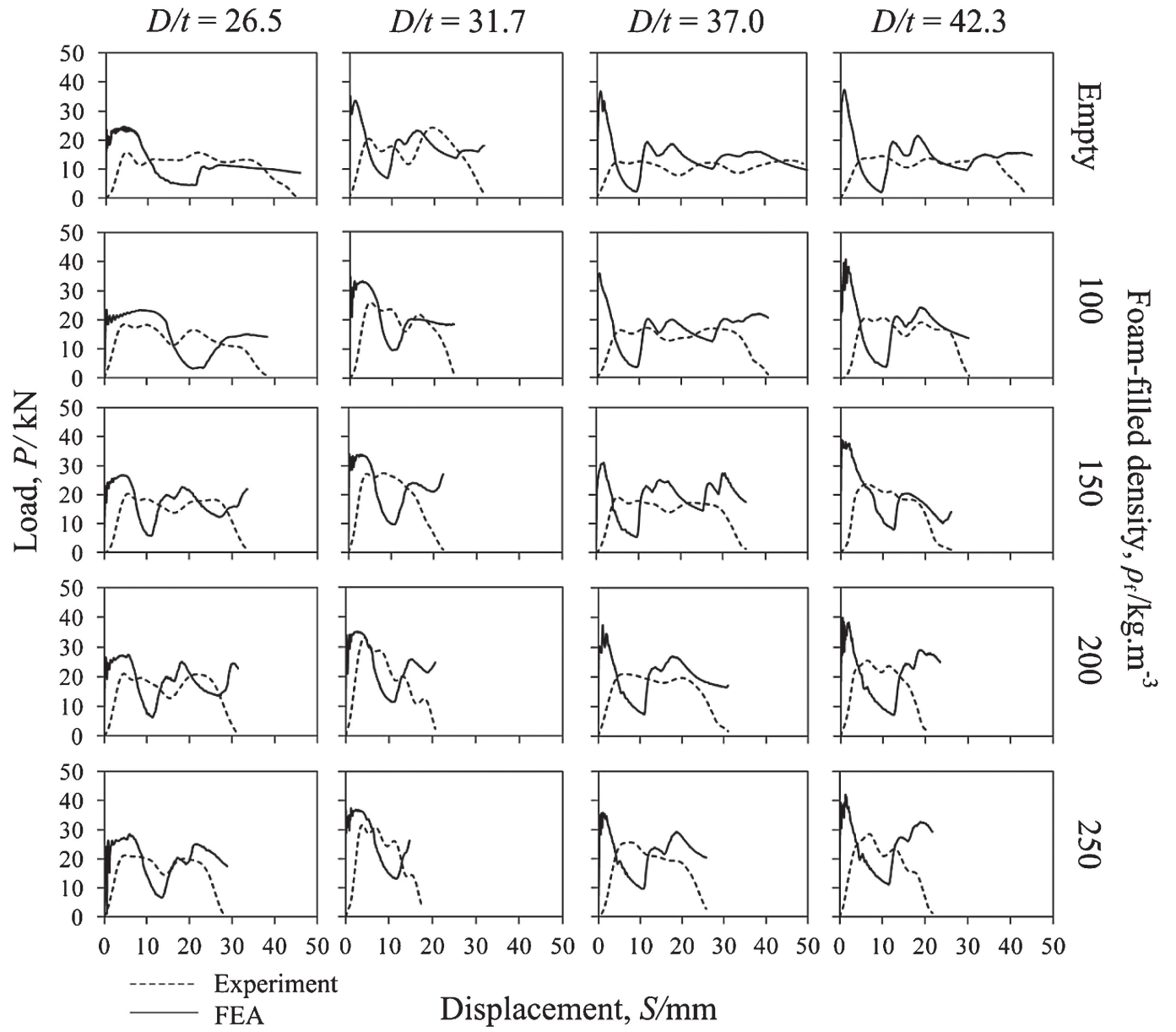

Fig. 4 Load-displacement curves of experiment and FE under impact load.

the value of load is increasing as the density of foam increases. This implies that the PU foam with higher density can resist higher impact energy and lift up the value of load in the load-displacement curve. From Fig. 4, one may noticed that the initial peak load of tube with $D / t$ of 31.7 is higher than other tubes in every foam density. This is the influence of thickness, the thickness of tube with $D / t$ of 31.7 is $1.3 \mathrm{~mm}$ while the rest are $1.2 \mathrm{~mm}$. The thicker tube usually offers higher value of initial peak because it can resist higher load than thinner tube. However, the peak load is not a main focus of this study.

\subsection{Behavior of collapse modes}

When the specimen was axially crushed, it normally deforms in some mode. The progressive collapse of foamfilled tubes is started by forming a folding lobe from one end. Then, as the previous lobe is completed, the adjacent folding lobe is formed on top and stack on each other. This process continues in series until the test is terminated. Figure 5 shows some examples of the collapse mode of specimens from the experiment compared to FE simulation. In general, there are 4 modes of collapse could be found in compressed tube. They are concertina mode (axisymmetric), diamond mode 
(asymmetric), buckling mode (asymmetric) and mixed mode (asymmetric). ${ }^{38)}$ These modes are closely depending on geometry of specimens. They are different in appearance and energy absorption capacity, as will be discussed more later. There are 3 collapse modes found in this study i.e., concertina mode, diamond mode and mixed (concertina with diamond) mode as shown in Figs. 5(a)-5(c). An example of deformed foam-filled tube in half section is shown Fig. 5(d). It is observed that the results from FE model agree well with experiment. In this study 3 -folds is found in experiment and 2-folds is found in FE model. Figure 5(e) shows an example collapse history of foam-filled tube under impact from the

(a)
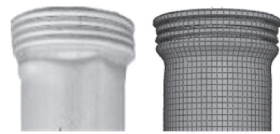

(c)

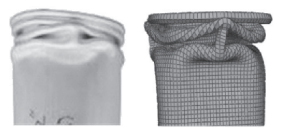

(e)

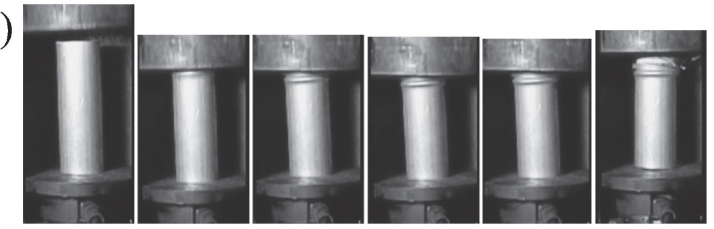

(f)
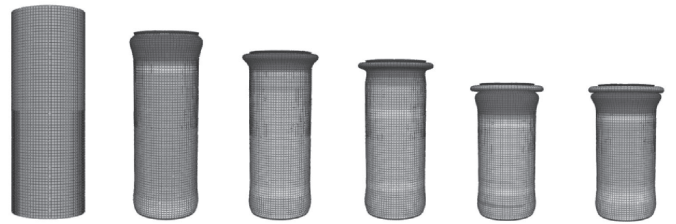

Fig. 5 Typical collapse mode under impact: (a) concertina mode $(D / t=$ 42.3 , empty), (b) diamond mode ( $D / t=31.7$, empty), (c) mixed mode $(D / t=37$, empty), (d) half view with foam-filled tube $(D / t=42.3$, $\left.\rho_{\mathrm{f}}=250\right)$, (e) deformation histories of experiment $\left(D / t=42.3, \rho_{\mathrm{f}}=200\right)$ and (f) deformation histories of FE simulation $\left(D / t=42.3, \rho_{\mathrm{f}}=200\right)$. experiment which recorded by high speed camera with speed 1200 frame/s. The collapse history of FE simulation is in similarly collapse pattern with experimental result as shown in Fig. 5(f).

The terminal collapse modes of all tests are summarized in Fig. 6. For the empty tubes with $D / t$ ratios of 26.5 and 31.7 , they collapse in diamond mode and transfer into mixed mode when $D / t$ ratio is increased to 37 and 42.3 . It is observed that the tubes with small $D / t$ are normally failed in diamond mode or mixed mode. This is because their thickness is high and cannot form a completed ring to be concertina mode. Considering of foam-filled tube with density $100 \mathrm{~kg} \cdot \mathrm{m}^{-3}$ with $D / t$ ratio $26.5,31.7$, and 37 , they collapse in mix mode, while the tube with $D / t$ ratio 42.3 is transformed into concertina mode and also increasing in the number of folds. In case of foam-filled tube with $150 \mathrm{~kg} \cdot \mathrm{m}^{-3}$ density and $D / t$ ratio 26.5 , the tube is collapse in mix mode and some tubes begin to transfer into concertina mode. In this case with higher $D / t$ ratio, all tube is collapsed into concertina mode. In case of foam-filled tube with foam density 200 and $250 \mathrm{~kg} \cdot \mathrm{m}^{-3}$, only concertina mode is observed. One reason of why concertina mode is usually found in tubes with higher density foam may come from the property of foam. The foam with higher compression normally under goes high compact and more solid, as can be seen in the final stage of stressstrain curve in Fig. 1(b). The more solidity of foam column in tube, the impact load can be distributed to tube wall more effectively. Hence local buckling along the hoop of tube can be expected and then the completed concertina ring is formed.

The deformation mode in Fig. 6 indicates that while the density of foam increases, the tendency of collapse mode is transformed from asymmetric mode to concertina mode. It should be noted that the concertina mode is normally preferable mode because it provides higher energy absorption and more uniform load variation during the collapse process. Normally, the load-displacement curve of concertina mode is

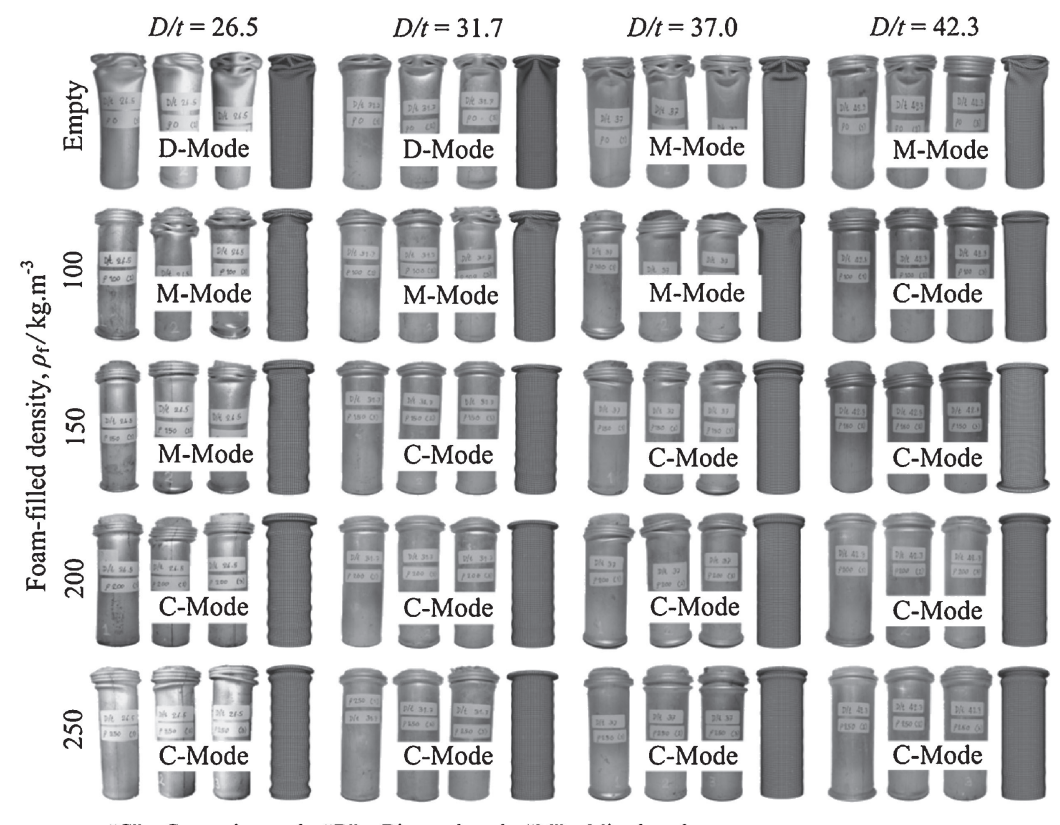

"C" = Concertina mode, "D" = Diamond mode, "M" = Mixed mode

Fig. 6 Terminal collapse tubes of experiment compared to FE simulation. 


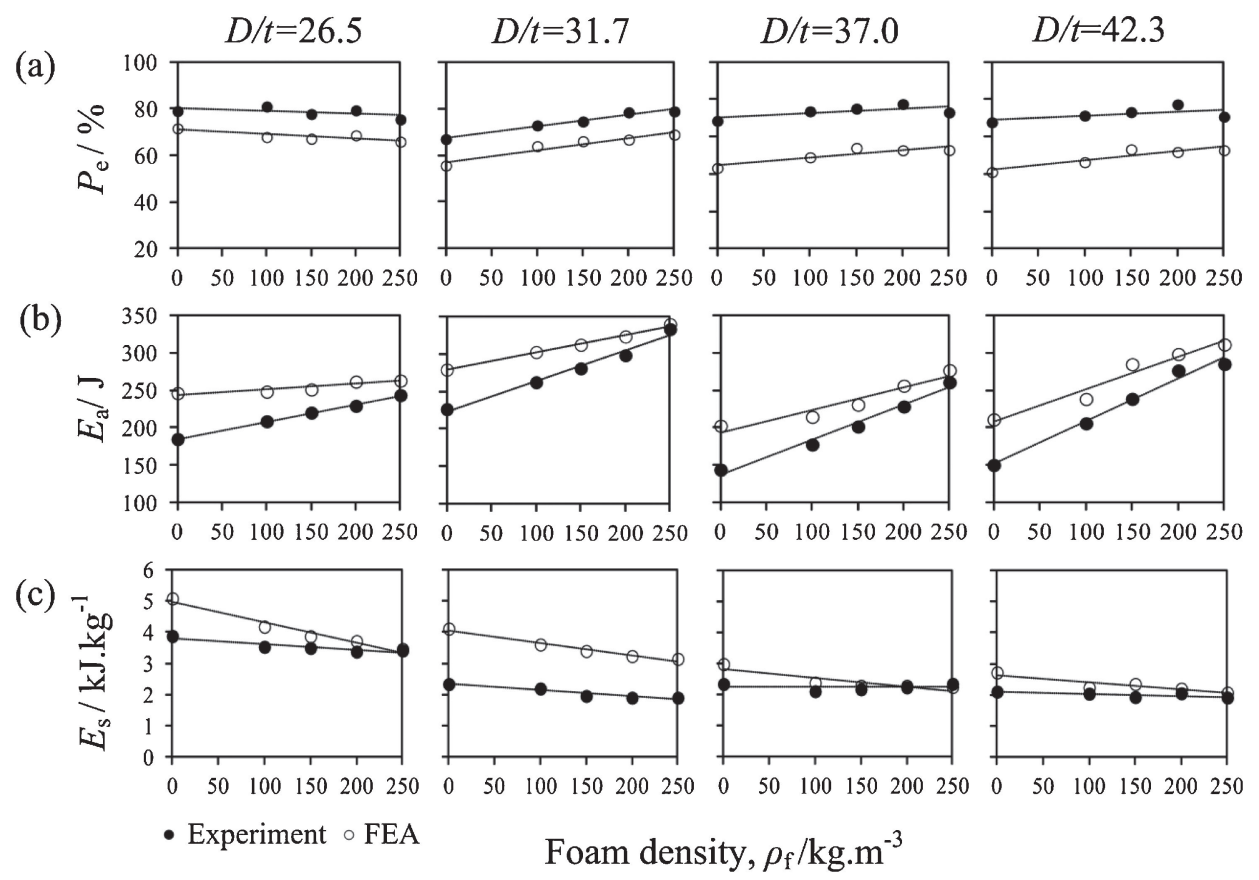

Fig. 7 Comparison results between experiment and FE simulation with different foam densities and $D / t$ values: (a) load efficiency, (b) energy absorption and (c) specific energy absorption.

more uniform than other modes. As the result, the mean crushing load is high compared to peak load and helps to reduce deceleration while impacting. This has been confirmed by many investigators such as Andrews et al. ${ }^{38)}$ and Pled et al. ${ }^{39)}$ who indicated that the concertina mode is better than other modes and higher specific energy absorption than the diamond mode. In addition, the study of Gupta et al. ${ }^{40)}$ also revealed that the crushing load of concertina mode is higher than diamond mode in the specimen with same geometry and boundary condition. On the crash behavior, concertina mode is the better for body tolerance in respect to reducing of acceleration and deceleration of human body. It is postulated that PU foam which filled in tube helps distributing impact load to the tube wall more effective, resulting more uniform mode and higher number of folds. This implies that one may achieve preferable mode (concertina mode) and increase number of folds by filling tube with PU foam. Considering the FE model shown in Fig. 6, it is observed that the FE results of collapse modes are agreed well with experimental results.

\subsection{Effect of foam filled on crashworthiness parameter}

The crashworthiness parameters were calculated with $15 \mathrm{~mm}$ stroke of a deformed specimen on load-displacement curve by using eqs. (1)-(3). The results of $E_{\mathrm{a}}, E_{\mathrm{s}}$ and $P_{\mathrm{e}}$ in Fig. 7 are the average values from three tests. The values of standard derivation of those results were between 2.10 $14.36 \mathrm{~J}$ or $0.75-5.04 \%$ for $E_{\mathrm{a}}$, between $0.015-0.20 \mathrm{~kJ} \cdot \mathrm{kg}^{-1}$ or $0.75-5.91 \%$ for $E_{\mathrm{s}}$ and between $0.56-4.82 \%$ for $P_{\mathrm{e}}$. These variations are quite small, hence the average values are considered acceptable for further discussion. From the results shown in Fig. 7, it is observed that the values of energy absorption and specific energy absorption from FE model are higher than the experimental result. The discrepancy is attributed to the imperfection of specimens in the test as well as some assumptions in FE model i.e., the boundary condition and material properties. The value of load efficiency from experiment is higher than that of FE result because the effect of peak load from FE model is higher than experimental result. Each crashworthiness parameter is discussed individually as follow.

\subsubsection{Response of load efficiency}

The load efficiency is plotted regarding to different $D / t$ values and shown in Fig. 7(a). As discussed previously, the value from experiment is higher than the FEA result. However, they are in the same trend with considerably constant discrepancy. For $D / t$ values of $31.7,37$ and 42.3 , the load efficiency are increasing as the value of foam density is increased. The increments of load efficiency for tubes with foam density of $100,150,200$ and $250 \mathrm{~kg} \cdot \mathrm{m}^{-3}$ are about $2-9,8-11,13-17$, and $4-18 \%$ compared to empty tubes respectively. This indicates that by filling foam in aluminum tube, the load efficiency may be enhanced. This implies that the foam helps to manage impact load by distributing impact energy into main structure more smoothly, resulting the reduction of high peak and elevates the mean load. This could help preventing deceleration that occurs in vehicle accident. However, in case of $D / t=26.5$, it is found that the value of load efficiency is almost constant or slightly decreased as the foam density is increasing. In this case the wall thickness of tubes is the highest compared to other. Hench the influence of foam is diminished because the stiffness of metal is much higher than foam.

\subsubsection{Response of energy absorption}

Considering the energy absorption in the whole collapse process, the value of energy absorption is plotted and shown in Fig. 7(b). It is observed that the value of energy absorption from FEA is higher than that of experiment. This is due to the assumptions in FE model as mentioned earlier. However, the value of energy absorption from $\mathrm{FE}$ and experiment are in the 
same trend. It is observed that the value of energy absorption is increased as the value of foam density is increasing.

For tubes with $D / t=26.5$, the value of energy absorption is increased by $12.8,19,23.9$, and $31.6 \%$ for $100,150,200$ and $250 \mathrm{~kg} \cdot \mathrm{m}^{-3}$ foam density respectively compared to empty tube. In case of tube with $D / t=31.7$, the energy absorption is increased by $15.8,24,31.6$ and $47 \%$ when filled with foam of $100,150,200$ and $250 \mathrm{~kg} \cdot \mathrm{m}^{-3}$ density. In case of tube with $D / t=37$, the energy absorption is increased by $23.3 \%, 40 \%, 58.4 \%, 80.8 \%$ and for the $D / t=42.3$, is increased by $36.8,58.6,83.7$, and $89.5 \%$ when filled with foam of $100,150,200$ and $250 \mathrm{~kg} \cdot \mathrm{m}^{-3}$ foam density respectively. From the previous discussion, it is noticed that the increment of the energy absorption is higher in thinner tubes (higher $D / t$ ). This is because the influence of foam is dominant in thin tube. From Fig. 7(b) it is also noticed that the increment of $E_{\mathrm{a}}$ is also related to the change of failure mode. Considering the specimens with $D / t=26.5$, the empty tube failed in diamond mode and changed to mixed mode after filled with foam density of $100-150 \mathrm{~kg} \cdot \mathrm{m}^{-3}$ and changed further to concertina mode with density of foam $200-250 \mathrm{~kg} \cdot \mathrm{m}^{-3}$. As the collapse modes changed from diamond mode to mixed mode and to concertina mode, the value of $E_{\mathrm{a}}$ is increasing. For tube with $D / t=26.5$, it is observed that the value of $E_{\mathrm{a}}$ is increasing about $18-19 \%$ and 24-32\% when modes change from diamond mode to mixed and from mixed mode to concertina mode respectively. It is also observed for tube with $D / t=31.7$ that the empty tube failed in diamond mode and changed to mixed mode for density of $100 \mathrm{~kg} \cdot \mathrm{m}^{-3}$ and then further changed to concertina mode after filled with density of 150,200 and $250 \mathrm{~kg} \cdot \mathrm{m}^{-3}$. Similarly, as the $D / t=31.7$ tube changes its mode from diamond mode to mixed mode to concertina mode, it is obviously seen that the value of $E_{\mathrm{a}}$ is also increasing. For this tube, the value of $E_{\mathrm{a}}$ is increasing about 24 and $47 \%$ when modes change from diamond mode to mixed and from mixed mode to concertina mode respectively. Similar phenomenon can be observed for tubes with $D / t=37.0$ and 42.3. The increments of their $E_{\mathrm{a}}$ are about $40-80 \%$ and $37-90 \%$ respectively when their modes change from mixed mode to concertina mode. Therefore, it could be concluded that the tubes with foam filled could be changed their collapse modes to concertina modes and higher energy absorption can be expected because concertina mode normally provides higher $E_{\mathrm{a}}$.

\subsubsection{Response of specific energy absorption}

The relationship of specific energy absorption and value of foam density is shown in Fig. 7(c). It is observed that the value of specific energy absorption from FE simulation is slightly higher than experiment, but still in a similar pattern. In general, it is observed that the value of the specific energy absorption of foam filled tube is slightly decreased as the value of foam density increases. Considering the experimental results, it is found that the value of specific energy absorption of foam filled tube, compared to empty tube, is decreased by $3-10 \%, 7-16 \%, 2-18 \%$, and $0-18 \%$ for foam density of $100,150,200$ and $250 \mathrm{~kg} \cdot \mathrm{m}^{-3}$ respectively. This implies that, although the additional foam can enhance the energy absorption capacity of tube, it also adds more weight to the structure.

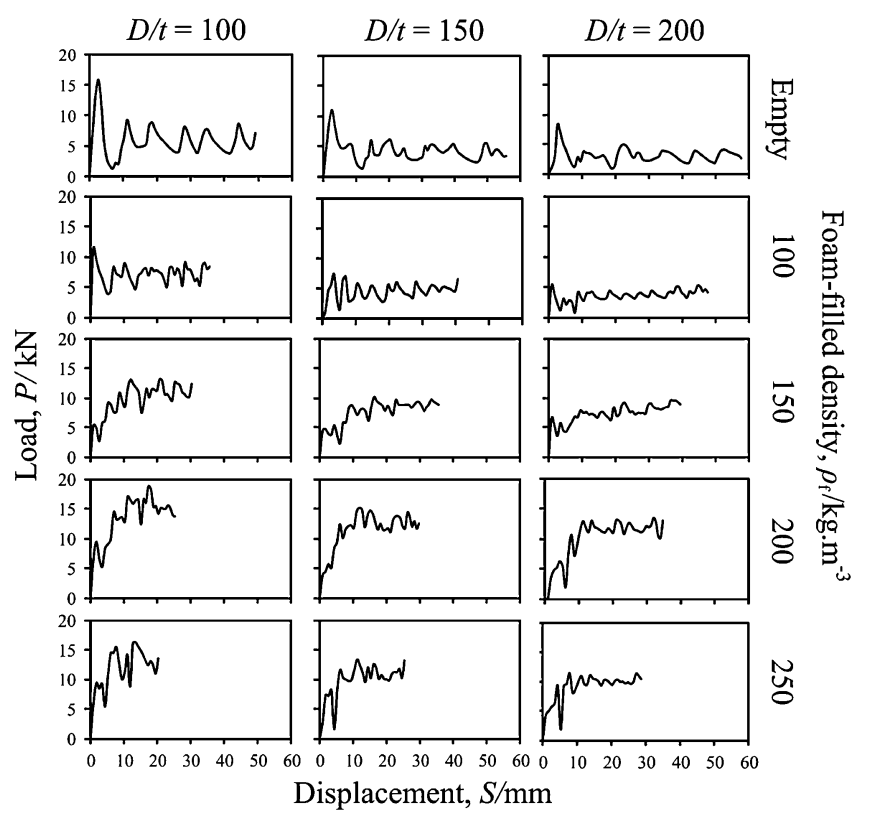

Fig. 8 Load-displacement curves of empty and foam-filled tube predict on FE simulation.

\subsection{Crashworthiness prediction using FE model}

As it is observed in the previous topics that the FE models provided good agreement to the experimental results. Hence, the model was used for further investigation on tubes with $D / t$ of 100,150 and 200 . The geometrical detail of tubes in FE model is shown in Table 1 . They were filled with foam of the same densities, which are 0,100, 150, 200 and $250 \mathrm{~kg} \cdot \mathrm{m}^{-3}$. The test procedure is similar to that explained in topic 2.3 and 2.4 .

The load-displacement curves from FE simulation are shown in Fig. 8. It is observed that the initial peak load is decreasing as the value of $D / t$ increases. This is because the thickness of high $D / t$ tube is smaller, therefore it cannot stand for high impact load. It is also observed that the loaddisplacement curves of foam-filled tubes with densities from $150-250 \mathrm{~kg} \cdot \mathrm{m}^{-3}$ tend to increase as the collapse progress. This is the influence of foam which becomes more solid at lager compression and elevates the value of load. This, therefore, gives higher value of $E_{\mathrm{a}}$ and will be discussed later.

The collapse mode archived from FE model are shown in Fig. 9. As can be seen from Fig. 9 that the empty tubes with $D / t=26.5$ and 31.7 failed in diamond mode and changed to mixed mode at $D / t=37.0$ and 42.3. Empty tubes with $D / t=100,150$ and 200 failed in concertina mode. This confirms the former conclusion that thick empty tube (low $D / t$ ) tends to fail in diamond mode, while empty thin tube (high $D / t$ ) would fail in concertina mode. Considering the influence of PU foam, the tubes with $D / t=26.5$ and 31.7 failed in diamond mode for empty tube and then transferred to mixed mode and concertina mode as the foam density is higher. For tubes with $D / t=37.0$ and 42.3 , they failed in mixed mode for empty tubes and then changed to concertina mode when the density of foam is increasing. In case of tube with $D / t=100,150$ and 200, they failed in concertina mode for every foam density. Similar to the discussion in previous 


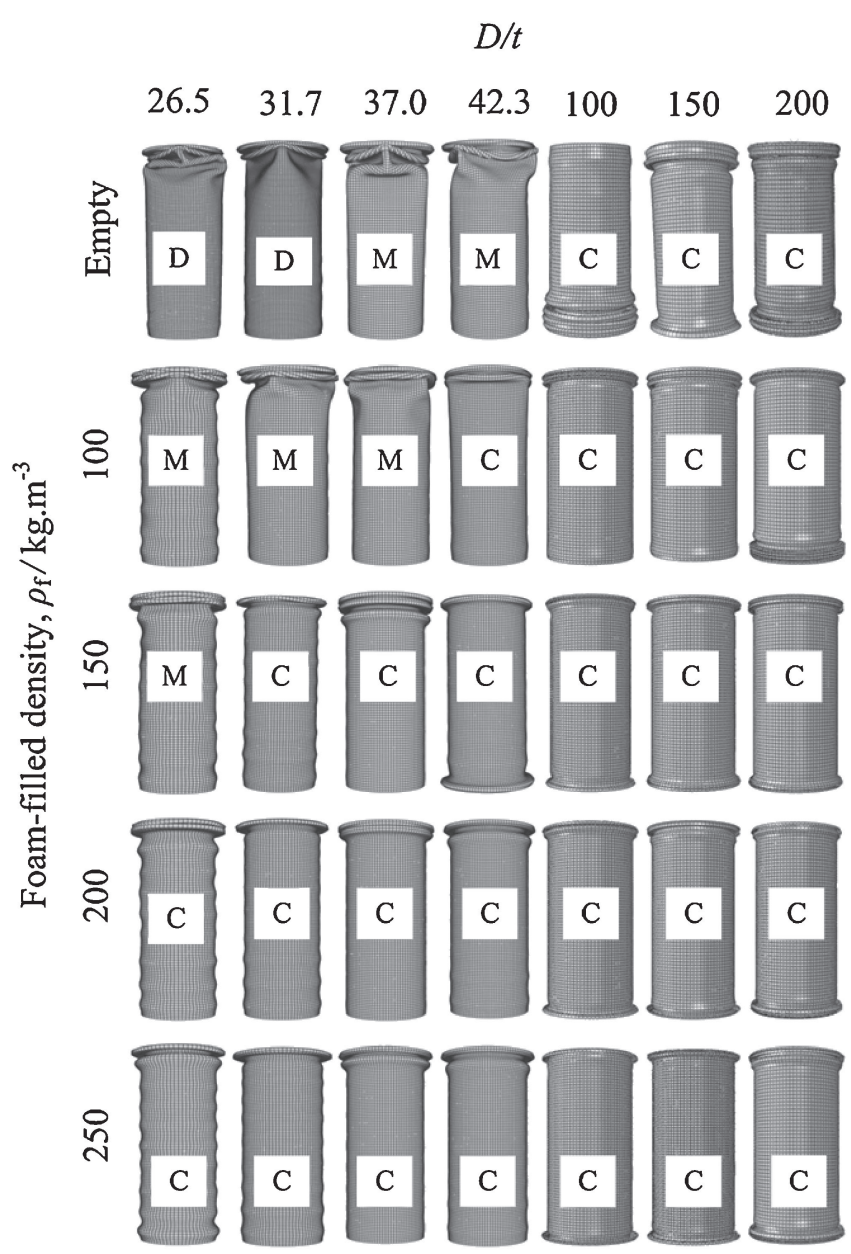

"C" = Concertina mode, "D" = Diamond mode, "M" = Mixed mode

Fig. 9 Terminal collapse tubes of FE simulation.

sections, this result implies that PU foam helps changing mode of collapse from asymmetric mode (diamond mode or mixed mode) to be axisymmetric mode (concertina mode).

The energy absorption values $\left(E_{\mathrm{a}}\right)$ achieved from simulation are plotted and shown in Fig. 10(a) and 10(b) when regarding to $D / t$ ratio and foam density, respectively. Considering Fig. 10(a), it is seen that the value of $E_{\mathrm{a}}$ tends to decrease as the value of $D / t$ is increasing. This is because high $D / t$ tube normally has small wall thickness, therefore it cannot absorb high impact energy. Considering Fig. 10(b), it is observed that $E_{\text {a }}$ of foam filled tube is increasing as the foam density increases. This is partly because the foam helps to support some energy and also helps to change collapse mode to be concertina mode which offers higher energy absorption.

\section{Conclusion}

The present study has presented the impact behaviour of PU foam-filled tubes with different $D / t$ ratios and foam densities. The computed energy absorption, specific energy absorption, load efficiency, and deformed shapes under collapse mode at different densities of foam are found to agree well between those of experiment and FE simulation. This study also conducted a series of FE simulation to
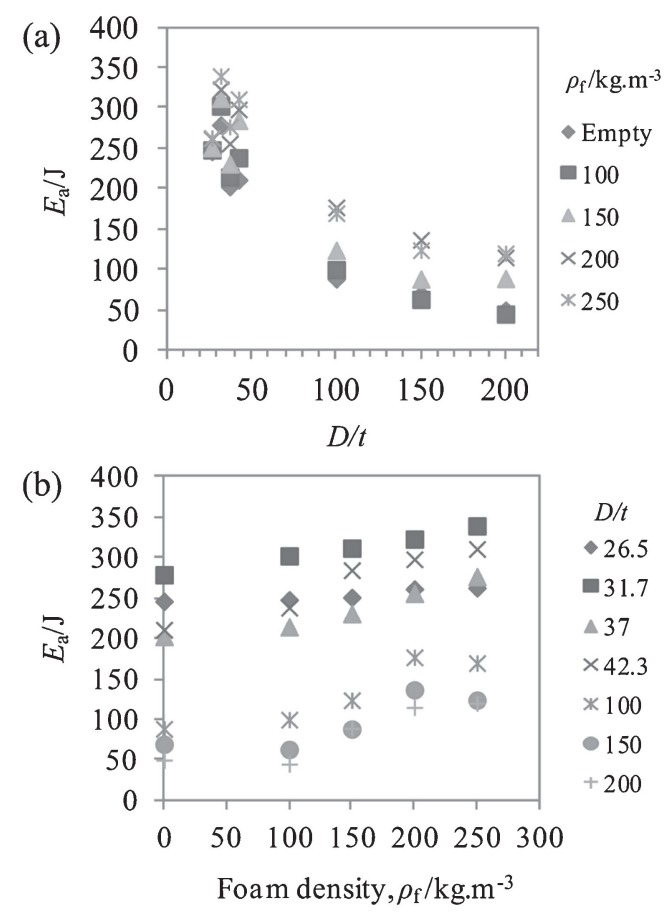

Fig. 10 The energy absorption of FE simulation with: (a) concerning by $D / t$ ratios, (b) concerning by foam-filled density.

investigate more specimens with higher. Considering response of impact force, it is found that the initial peak load at the first lobe on load-displacement curves of simulation is higher than that of the experimental results. However, the mean load from the whole collapse process of experiment is agreed well with FE. Considering mode of collapse, the empty tube is generally collapsed in diamond mode with lower $D / t$ ratio and transfers to mixed mode and concertina mode when $D / t$ ratio increases. For the foam-filled tubes, they tend to change their collapse mode from diamond mode and mixed mode, then, to concertina mode as the $D / t$ ratio and foam density is increased. It can be said that the foam filled tube is changed its collapse mode from asymmetric to symmetric mode at higher foam density. Considering the energy absorption, the foam-filled tube can absorb higher energy when the density of foam is increasing. However, the value of specific energy absorption seems to be slightly decreased when the density of foam is increased. It is also found that the foam filled tube can distribute impact energy more smoothly as the value of load efficiency is higher in higher density foam. In conclusion, it could be said that by filling PU foam in aluminum tube, higher energy absorption and low deceleration can be expected. However, weight of PU foam adding up in the structure is pretty high as the specific energy absorption is slightly goes down.

\section{Acknowledgments}

The authors thank the Office of the Higher Education Commission, Thailand, for the supporting grant under the program Strategic Scholarships for Frontier Research Network for the PhD Program. Also, appreciation is expressed to Bob Tremayne of the Office of International Relations at Ubon Ratchathani University for assistance with English. 


\section{REFERENCES}

1) S. R. Guillow, G. Lu and R. H. Grzebieta: Int. J. Mech. Sci. 43 (2001) 2103-2123.

2) G. M. Nagel and D. P. Thambiratnam: Int. J. Impact. Eng. 32 (2006) 1595-1620.

3) I. W. Hall, O. Ebil, M. Guden and C. J. Yu: J. Mater. Sci. 36 (2001) 5853-5860.

4) J. M. Alexander: J. Mech. Appl. Math. 13 (1960) 10-15.

5) W. Abramowicz and N. Jones: Int. J. Impact. Eng. 2 (1984) 263-281.

6) A. A. Singace, H. Elsobky and T. Y. Reddy: Int. J. Solids Struct. 32 (1995) 3589-3602.

7) A. A. Singace and H. Elsobky: Int. J. Solids Struct. 33 (1996) $3517-$ 3538.

8) A. G. Mamalis, D. E. Manolakos, M. B. Ioannidis, P. K. Kostazos and C. Dimitriou: Thin Wall. Struct. 41 (2003) 891-900.

9) A. G. Mamalis, D. E. Manolakos, N. B. Ioannidis and P. K. Kostazos: Int. J. Crashworth. 10 (2005) 505-513.

10) M. Langseth, O. S. Hopperstad and A. G. Hanssen: Thin Wall. Struct. 32 (1998) 127-150.

11) M. Langseth, O. S. Hopperstad and T. Berstad: Int. J. Impact. Eng. 22 (1999) 829-854.

12) A. A. Nia and J. H. Hamedani: Thin Wall. Struct. 48 (2010) 946-954.

13) M. Yamashita, M. Gotoh and Y. Sawairi: J. Mater. Process. Tech. 140 (2003) 59-64.

14) N. K. Gupta and Venkatesh: Thin Wall. Struct. 44 (2006) 290-300.

15) M. R. Bambach: Thin Wall. Struct. 48 (2010) 440-452.

16) C. Hackmair, E. Werner and M. Pönisch: Comput. Mater. Sci. 28 (2003) 540-547.

17) H. Ning, G. M. Janowski, U. K. Vaidya and G. Husman: Compos. Struct. 80 (2007) 82-91.

18) Y. X. Li, Z. Q. Lin, A. Q. Jiang and G. L. Chen: Mater. Des. 24 (2003) $177-182$.

19) H. Huh, K. P. Kim, S. H. Kim, J. H. Song, H. S. Kim and S. K. Hong Int. J. Mech. Sci. 45 (2003) 1645-1660.
20) K. S. Lee, Y. J. Yang, W. C. Hwang and I. Y. Yang: Trans. Nonferr. Metal. Soc. China 19 (2009) s276-s279.

21) W. Abramowicz: Thin Wall. Struct. 41 (2003) 91-107.

22) L. Aktay, A. K. Toksoy and M. Güden: Mater. Des. 27 (2006) 556-565.

23) A. G. Hanssen, M. Langseth and O. S. Hopperstad: Int. J. Mech. Sci. 41 (1999) 967-993.

24) A. G. Hanssen, M. Langseth and O. S. Hopperstad: Int. J. Impact. Eng. 24 (2000) 475-507.

25) A. G. Hanssen, M. Langseth and O. S. Hopperstad: Int. J. Impact. Eng. 24 (2000) 347-383.

26) M. Miyazaki and H. Negishi: Mater. Trans. 44 (2003) 1566-1570.

27) Y. Yamada, T. Banno, Z. K. Xie and C. Wen: Mater. Trans. 46 (2005) 2633-2636.

28) W. Y. Yan, E. Durif, Y. Yamada and C. Wen: Mater. Trans. 48 (2007) 1901-1906.

29) Z. Ahmad and D. P. Thambiratnam: Compos. Struct. 87 (2009) 186197.

30) D. Karagiozova, M. Alves and N. Jones: Int. J. Impact. Eng. 24 (2000) 1083-1115.

31) S. A. Meguid, M. S. Attia and A. Monfort: Mater. Des. 25 (2004) 183189.

32) A. Ghamarian and M. T. Abadi: Thin Wall. Struct. 49 (2011) 743-752.

33) L. Mirfendereski, M. Salimi and S. Ziaei-Rad: Int. J. Mech. Sci. 50 (2008) 1042-1057

34) S. Poonaya, U. Teeboonma and C. Thinvongpituk: Thin Wall. Struct. 47 (2009) 637-645.

35) M. Seitzberger, F. G. Rammerstorfer, R. Gradinger, H. P. Degischer, M. Blaimschein and C. Walch: Int. J. Solids Struct. 37 (2000) 4125-4147.

36) A. Ghamarian and M. T. Abadi: Thin Wall. Struct. 49 (2011) 743-752.

37) S. P. Santosa, T. Wierzbicki, A. G. Hanssen and M. Langseth: Int. J. Impact. Eng. 24 (2000) 509-534.

38) K. R. F. Andrews, G. L. England and E. Ghani: Int. J. Mech. Sci. 25 (1983) 687-696.

39) F. Pled, W. Yan and C. Wen: 5th Australasian Congress on Applied Mechanics, (2007) pp. 178-183.

40) N. K. Gupta and Nagesh: Int. J. Mech. Sci. 48 (2006) 210-223. 